\title{
Novel design and analysis of RF MEMS shunt capacitive switch for radar and satellite communications
}

\author{
Maham Kamil Naji ${ }^{1}$, Alaa Desher Farhood ${ }^{2}$, Adnan Hussein Ali ${ }^{3}$ \\ ${ }^{1}$ Institute of Techonology, Middle Technical University, Iraq \\ ${ }^{2,3}$ Technical Electronics Dept., Technical Instructors Training Tnstitute, Middle Technical University, Iraq
}

\begin{tabular}{|c|c|}
\hline Article Info & ABSTRACT \\
\hline Article history: & In this paper, a new type of Radio Frequency Micro-Electro-Mechanical \\
\hline Doraind 1 20 2010 & System (RF-MEMS) shunt capacitive switch is designed and studied. RF \\
\hline Received Aug 30, 2018 & MEMS switch has a number of advantages in a modern telecommunication \\
\hline Revised Dec 10, 2018 & system such as low power consumption, easy to fabricate and power \\
\hline Accepted Jan 12, 2019 & $\begin{array}{l}\text { handling capacity at radio frequency. At high frequency applications, this } \\
\text { switch shows very superior performance due to which it now became one of }\end{array}$ \\
\hline Keywords: & $\begin{array}{l}\text { the key elements for RF application. In this proposed design, an innovative } \\
\text { type of MEMS switch is designed. The MEMS switch structure consists of }\end{array}$ \\
\hline Capacitive shunt & substrate, co-planar waveguide $(\mathrm{CPW})$, dielectric material and a metallic \\
\hline CPW & bridge. The proposed MEMS switch has a dimension of $508 \mu \mathrm{m} \times 620 \mu \mathrm{m}$ \\
\hline HFSS & permittivity of the substrate is 12.9 . This proposed MEMS switch is designed \\
\hline Insertion loss & and simulated in both UP $(\mathrm{ON})$ state and DOWN (OFF) state. The proposed \\
\hline MEMS switch & RF-MEMS switch is designed and simulated using Ansoft High frequency \\
\hline Return loss & structure simulator (HFSS) electromagnetic simulator. The simulated result \\
\hline RF-MEMS & $\begin{array}{l}\text { shows better performance parameters such as return loss }(<-10 \mathrm{~dB}) \text { and } \\
\text { insertion loss }(>-0.5 \mathrm{~dB}) \text { in UP state, whereas return loss }(>-0.5 \mathrm{~dB}) \text { and } \\
\text { isolation }(<-10 \mathrm{~dB}) \text { in DOWN state. This switch has good isolation } \\
\text { characteristics of }-43 \mathrm{~dB} \text { at } 27 \mathrm{GHz} \text { frequency. }\end{array}$ \\
\hline
\end{tabular}

Copyright $\odot 2019$ Institute of Advanced Engineering and Science. All rights reserved.

\section{Corresponding Author:}

Maham Kamil Naji,

Technical Electronics Dept., Imstitute of Technology,

Middle Technical University, Baghdad, Iraq.

Email:mahamkamil73@gmail.com

\section{INTRODUCTION}

The term RF-MEMS means Radio Frequency Micro-Electro Mechanical System. Therefore it is combination of two different systems that is mechanical and electrical systems. The MEMS switch exhibit both mechanical and electrical characteristics during the function. The mechanical property helps to up and down movement of RF MEMS switch for the transmission of radio frequency signal through the CPW conductor [1,2]. This MEMS switch are extensively used for radio frequency applications [3]. Initially MEMS are used for several devices such as tempreture sensor, pressure sensor, gas chromatographs etc and at the same time MEMS switch are also used at low frequency applications [4-6]. The MEMS switches integrates the benefits of mechanical and semiconductor properties in small size. This property of MEMS switch can be used for radio frequency, hence called RF-MEMS switch.

Like MEMS switch, there have alos been several standard switches such as PIN diode and FET for the switching function at RF frequency. The RF-MEMS switch provides better performances such as low power consumption, high isolation, less noise, low insertion loss, high bandwidth than the conventional solid state PINdiode and FET switches [7-8]. However, for the designing and operation of RF-MEMS switch, it has also some disadvantages such as switching speed, low power handling capacity [9-11], electrostatic discharge [12-13], high actuation voltage, packaging and low switching lifetime [14]. In order to overcome 
the above challenges, several techniques have used like for switching speed of bridge, different types of shapes have been made on the bridge such as meander, push-pull [15-16]. Simillarly to decrease the actuation voltage of switch, a number of techniques such as by decreasing the spring constant of bridge [17-18], using piezoelectric actuation [19-22] and other several structures [23-24].

The RF MEM switches have excellent performances have not yet resulted in extensive applications in commercial systems mainly due to this technology has relative immaturity. RF MEM switches need determine performance over an environmental condition with a wide range before they can be really considered for system applications. More, the RF MEM switches packaging needs to be an equivalence with FETs as well as PIN diodes. Lastly, the switches lifetime need to be practically sufficient that is being addressed, thus, the requirements of a Lifetime for RF MEM switches covering a very broad range of the some applications, like cell phone mode switching, while other applications, like space based radar, need up to more cycles.

Our main aim in this paper is to decrease the actuation voltage, improving the switching speed and increasing the isolation characteristics of the proposed MEMS switch. This is a new approach to increase the result of RF- MEMS switch. For this, rectangular slots have made on the bridge arm to accomplish the lower spring constant and for minimizing the stickiness between bridge and electrode, some cylindrical type of holes are designed on the bridge structure.

In this Paper, the designed RF-MEMES switch is modeled in both electrical and mechanical domain and the important parameters of switch such as return loss, insertion loss, isolation and pull in voltage will analysed. RF-MEMS switch design procedure, working principle, mechanical and electrical analysis are described.

\section{RF MEMS SWITCH DESIGN}

A MEMS switch can be designed in different ways depending upon the need and applications such as series or shunt type according to signal flow, Ohmic or capacitive according to contact type, electrostatic or magnetostatic according to actuation method. In the proposed design, RF-MEMS switch consists of six layers such as substrate, oxide layer, CPW, dielectric material, anchors and metallic bridge as shown in Figure 1. Capacitive MEMS switch uses a thin dielectric material in between bridge and conducting electrode during the actuation period and it is used to prevent from direct contact between bridge and conducting electrode [25].

A typical cross sectional view of MEMS switch is shown in above Figure 2 . In the design, the substrate is GaAs material and its dimension is $508 \mu \mathrm{m} \times 620 \mu \mathrm{m}$ of thickness $500 \mu \mathrm{m}$. The dielectric permittivity of substrate is 12.9 .

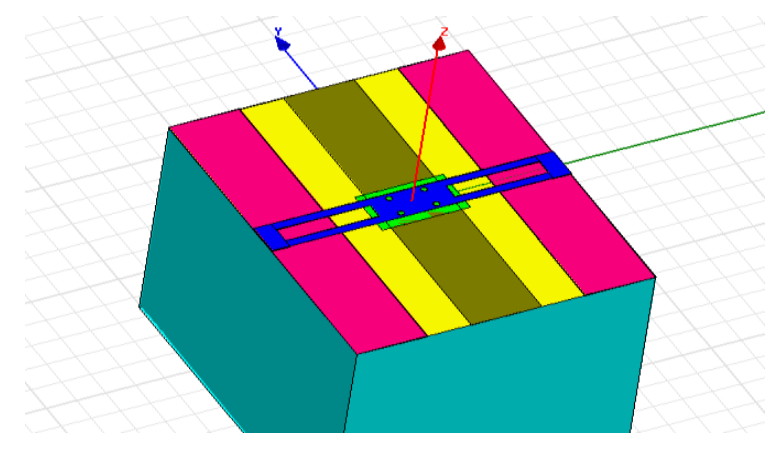

Figure 1. A general view of proposed RF-MEMS switch

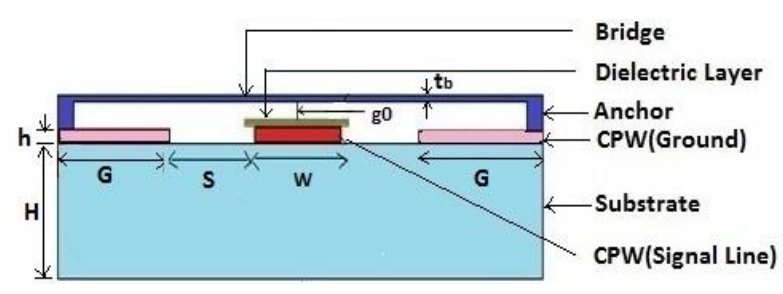

Figure 2. A cross-section view of proposed RF-MEMS switch 


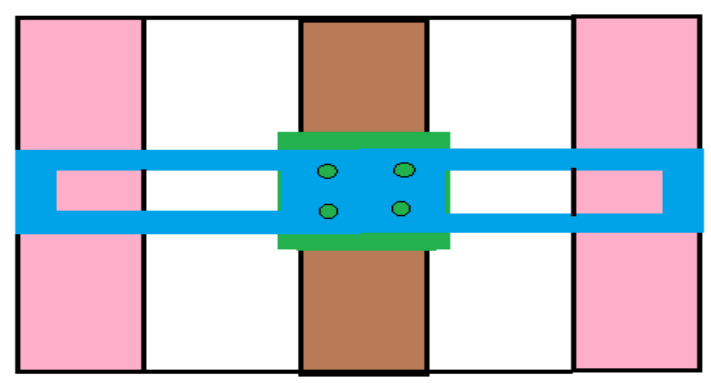

Figure 3. Top view of proposed RF-MEMS switch

A thin layer of silicon dioxide with thickness $0.5 \mu \mathrm{m}$ is deposited on the top surface of substrate. The switch consists of three identical CPW of same dimension in which the middle CPW behaves as a transmission conductor whereas others as ground. The dimension of CPW is $120 \mu \mathrm{m} \times 620 \mu \mathrm{m}$ with thickness $1 \mu \mathrm{m}$. To avoid the direct contact between metal to metal, a very thin layer of SiN dielectric material of dimesion $150 \mu \mathrm{m} \times 90 \mu \mathrm{m} \times 0.15 \mu \mathrm{m}$ is deposited on the top surface of center CPW. The RF MEMS switch is mechanically designed, a metal bridge is suspended ' $\mathrm{g} 0$ ' distance above the dielectric and it is also anchored at both ends to the ground CPW. The dimension of bridge is $508 \mu \mathrm{m} \times 60 \mu \mathrm{m}$ and thickness of $1 \mu \mathrm{m}$. The material used for bridge and gold is same ie gold. To reduce the actuation voltage and spring constant, two rectangular slots are made on the bridge surface. Similarly, On the surface of bridge, four identical cylindrical holes are designed with radius and height of $5 \mu \mathrm{m}$ and $1 \mu \mathrm{m}$ respectively. Due to this, the stickiness between bridge and electrode is reduce during the actuation. The proposed design can be shown in Figure 4 and the proposed RF MEMS switch desigining parameters are mention in Table 1.

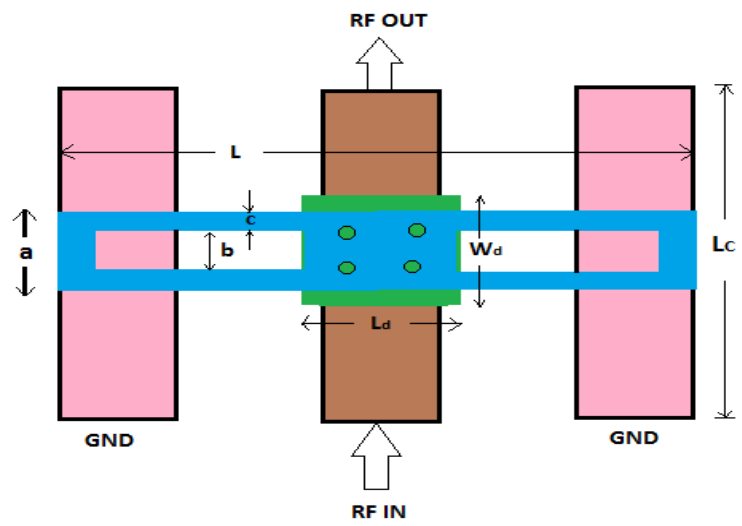

Figure 4. Geometry and dimensions of the proposed RF-MEMS switch

Table 1. RF MEMS Switch parameters and their dimensions

\begin{tabular}{cccc}
\hline Switch Parameters & $\begin{array}{c}\text { Dimension } \\
(\mu \mathrm{m})\end{array}$ & $\begin{array}{c}\text { Switch } \\
\text { Parameters }\end{array}$ & Dimension $(\mu \mathrm{m})$ \\
\hline W & 120 & $\mathrm{~L}$ & 508 \\
$\mathrm{G}$ & 120 & $\mathrm{a}$ & 60 \\
Lc & 620 & $\mathrm{t}_{\mathrm{b}}$ & 1 \\
$\mathrm{~S}$ & 74 & $\mathrm{~b}$ & 30 \\
$\mathrm{H}$ & 500 & $\mathrm{c}$ & 15 \\
$\mathrm{~h}$ & 1 & $\mathrm{Ld}$ & 150 \\
go & 2 & $\mathrm{Wd}$ & 90 \\
\hline
\end{tabular}

\section{PRINCIPLE WORKING OF RF MEMS SWITCH}

The MEMS switch can be work in two states ie up-state and down-state. In up-state, the MEMS switch passes the input radio signal through the input port to output port. When the actuation potential is applied to the switch, the suspended metallic bridge is moves towards the dielectric material and makes a short circuit to the electrode therefore all the input RF signal are passes to the ground. The up-state and 
down-state design of proposed switch are shown in Figure 5. The up-state and down-state working principle shown in Figure 6.

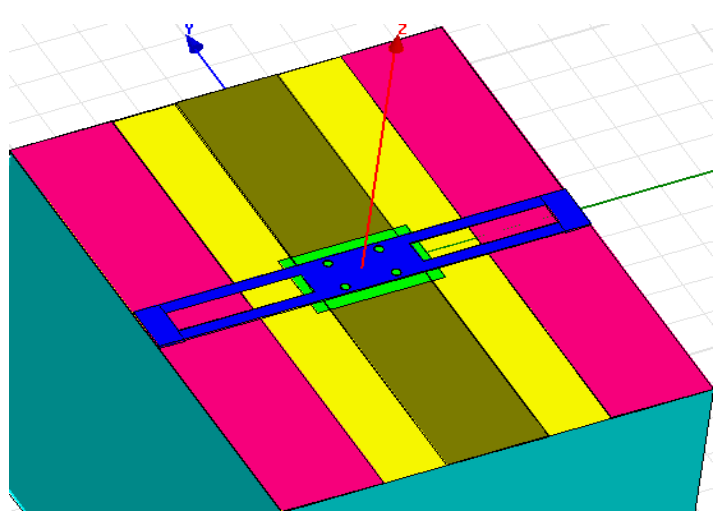

(a) UP-state view

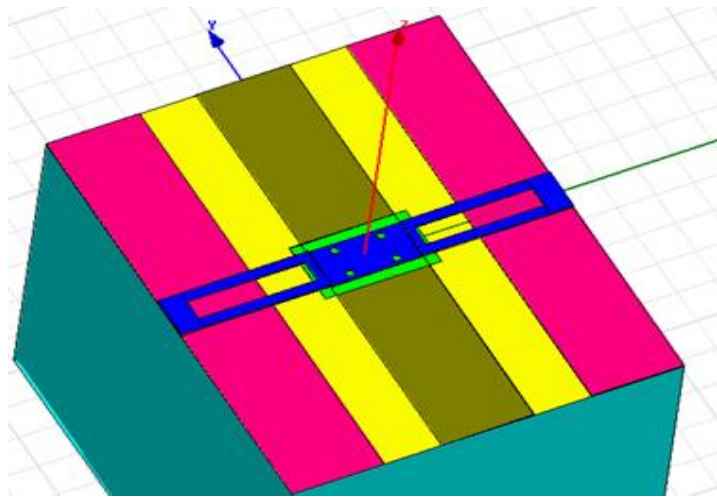

(b) DOWN-state view

Figure 5. HFSS design of proposed RF-MEMS switch views (a) UP-state and (b) DOWN-state

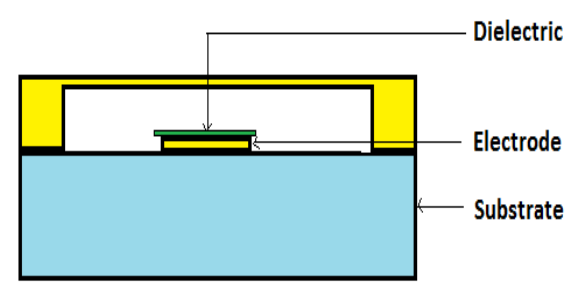

(a) UP-state

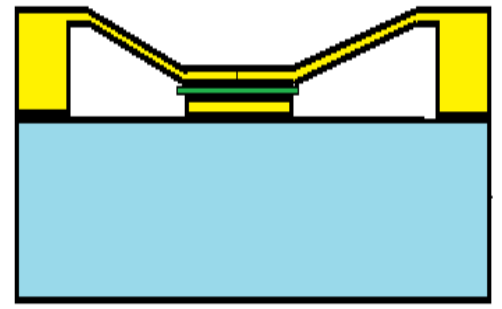

(b) DOWN-state

Figure 6. Working principle of RF-MEMS switch in (a) UP-state and (b) DOWN-state conditions

The actuation type is electrostatic actuation, which works on the Coulombs principle. As the charge is accumulated between the bridge and electrode and due to this an electrostatic force is created which has tendency to pull the bridge towards the electrode and the force is given by [26].

$$
F_{e}=\frac{\varepsilon_{0} A V^{2}}{2\left(g_{0}+\frac{t_{d}}{\varepsilon_{r}}\right)}
$$

where $\varepsilon_{0}$ is the dielectric constant of air, $\varepsilon_{\mathrm{r}}$ is the relative permittivity of the dielectric, $\mathrm{V}$ is the applied voltage, $\mathrm{g}_{0}$ is the distance between bridge and electrode, $\mathrm{A}$ is the area of contact and $t_{d}$ is the dielectric thickness.

\section{ELECTRICAL AND MECHANICAL MODEL ANALYSIS}

The RF-MEMS switch can be analysed in two different domains namely electrical domain and mechanical domain. In electrical domain, some electrical characteristics such as capacitance in both up and down states, shunt impedance, resonant frequency, return loss, insertion loss and isolation whereas in mechanical domain, some characteristics like pull in voltage, spring constant will becdiscussed.

\subsection{Electrical Model Analysis}

The electrical equivalent circuit model of the proposed MEMS switch is shown in Figure 7. It is modeled by using two transmission line and one lumped RLC structure of bridge along with the up and down state capacitance [27]. 
Input

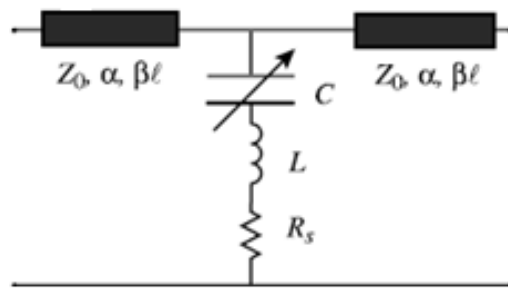

\section{Output}

Figure 7. Equivalent circuit model of proposed RF MEMS Capacitive shunt switch

The equivalent shunt impedance of the switch is given by:

$$
Z_{s}=R_{s}+j \omega L+\frac{1}{j \omega C}
$$

The shunt switch impedance is given by

$$
Z_{s}=\left\{\begin{array}{c}
\frac{1}{j \omega C}, f<<f_{\mathrm{o}} \\
R_{s}, f=f_{\mathrm{o}} \\
j \omega L, f>>f_{\mathrm{o}}
\end{array}\right.
$$

where the resonant frequency is given by

$$
f_{0}=\frac{1}{2 \pi} \frac{1}{\sqrt{L C}}
$$

From the above equation, the MEMS switch behaves as a capacitor when the frequency is below the resonant frequency $\left(f_{o}\right)$, and as inductor when the frequency is above the resonant frequency and acts as a pure resistive at the frequency equalts to resonant frequency. The up-state capacitance $\left(\mathrm{C}_{\mathrm{u}}\right)$ and down-state capacitance $\left(\mathrm{C}_{\mathrm{d}}\right)$ are given by

$$
\begin{aligned}
& C_{u}=\frac{\varepsilon_{0} A}{g_{0}+\frac{t_{d}}{\varepsilon_{r}}} \\
& C_{d}=\frac{\varepsilon_{0} \varepsilon_{r} A}{t_{d}}
\end{aligned}
$$

By using the value of $C_{u}$ and $C_{d}$, the return loss $\left(S_{11}\right)$ in up-state and the insertion loss $\left(S_{21}\right)$ in downstate are given by

$$
\begin{aligned}
& S_{11}=\frac{-j \omega C_{u} Z_{0}}{2+j \omega C_{u} Z_{0}} \\
& S_{21}=\frac{1}{1+j \omega C_{d} Z_{0} / 2}
\end{aligned}
$$




\subsection{Mechanical Model Analysis}

For this type of shunt capacitive MEMS switch, the pull in voltage is given by:

$$
V_{p}=\sqrt{\frac{8 k}{27 A \varepsilon_{0}} g_{0}{ }^{3}}
$$

where the pull in voltage depends upon the spring constant of the bridge material $(\mathrm{K})$, air gap $\left(\mathrm{g}_{\mathrm{o}}\right)$ between beam and electrode and contact area (A). The lower pull in voltage can be obtain by reducing the value of spring constant (K) and air gap (go) and also increasing the value of contact area. But air gap can not be decrese as much as low due to charge effect. Similarly the contact area, A also can not be increase due to the stickiness issue during the switching period.

\section{SIMULATION AND RESULT ANALYSIS}

The design and simulation of the proposed RF-MEMS switch is done with the help of Ansoft High Frequency Structure Simulator (HFSS) simulation tool [28]. The simulation of switch is performed for both up and down states.

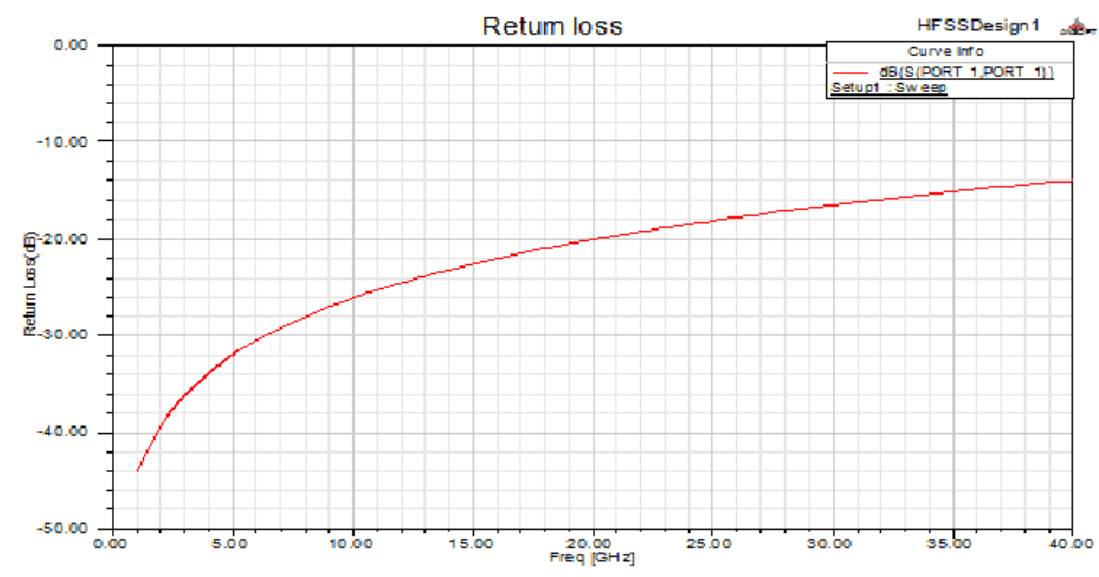

(a) Return Loss $\left(\mathrm{S}_{11}\right)$

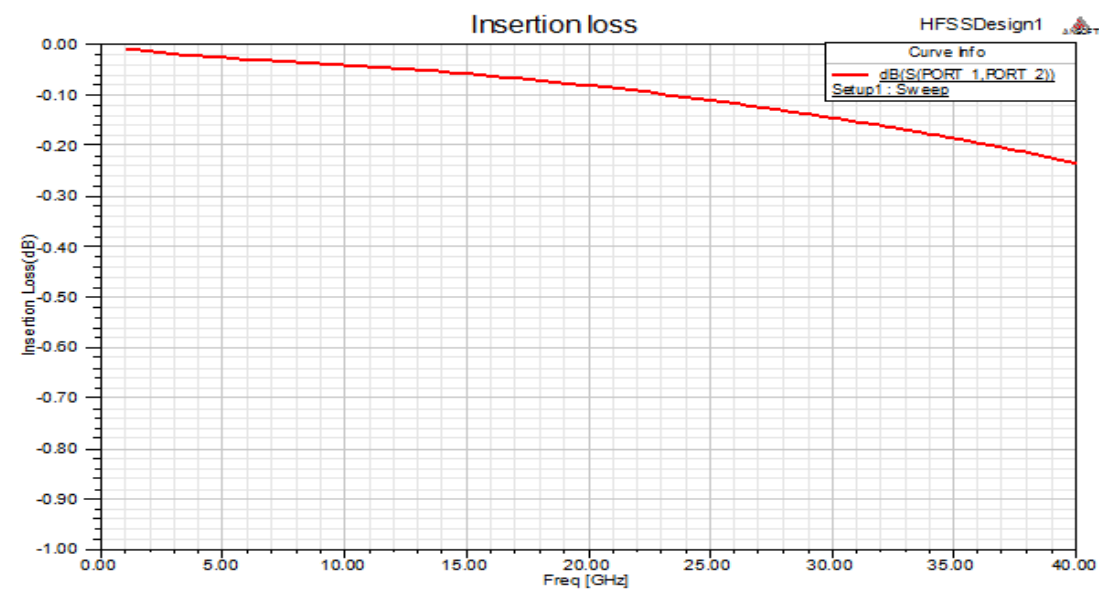

(b) Insertion Loss $\left(\mathrm{S}_{12}\right)$

Figure 8. Simulated results of proposed RF MEMS shunt capacitive switch in UP-state (a) Return Loss (b) Insertion Loss 


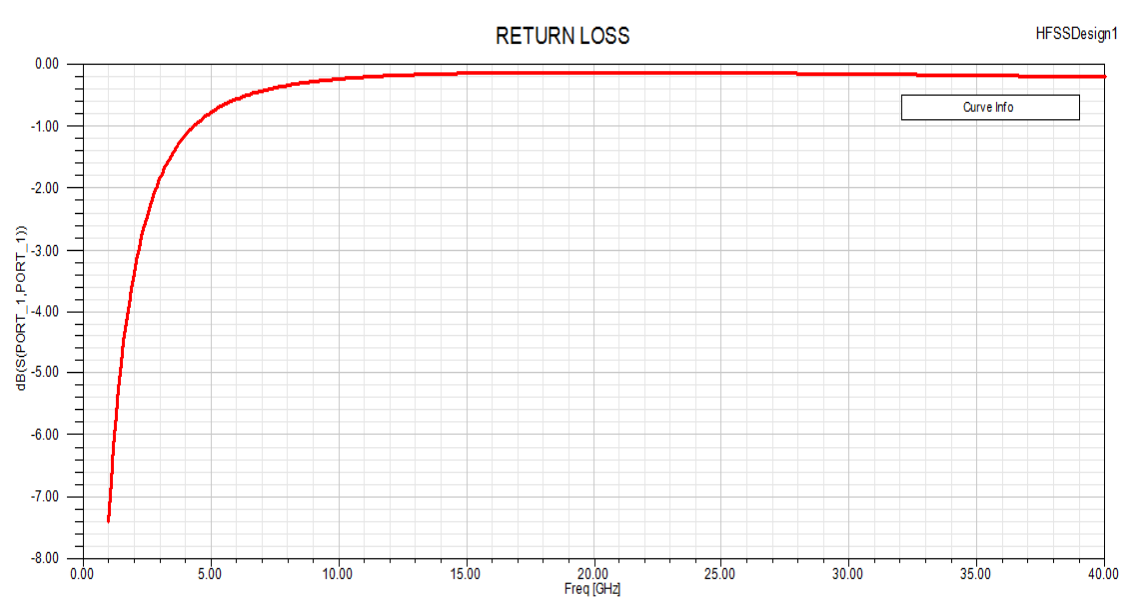

(a) Return Loss $\left(\mathrm{S}_{11}\right)$

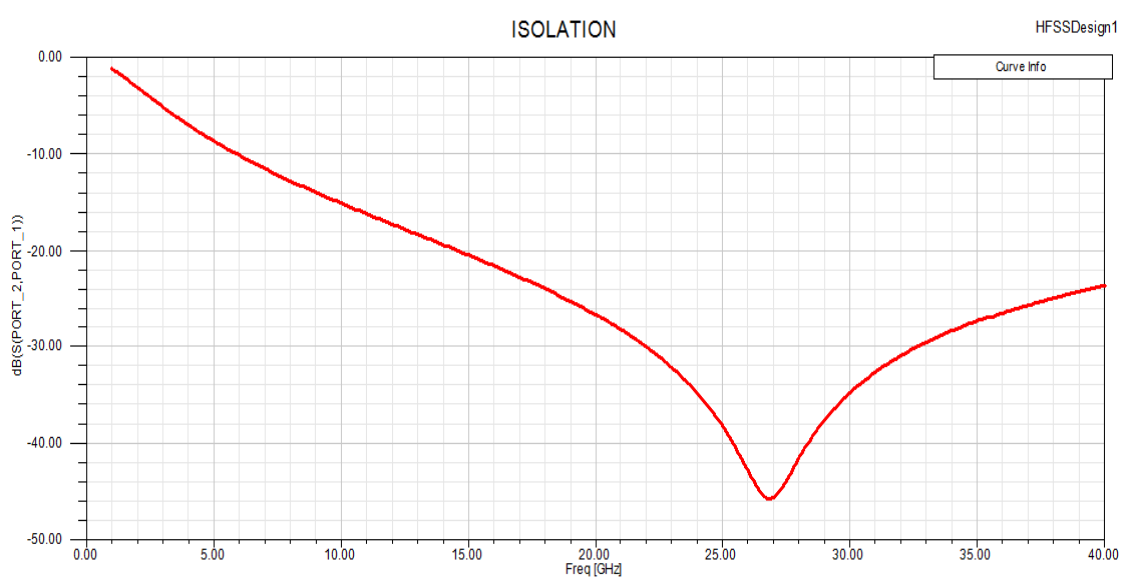

(b) Isolation $\left(\mathrm{S}_{21}\right)$

Figure 9. Simulated results of proposed RF MEMS shunt capacitive switch in DOWN-state (a) Return Loss (b) Isolation

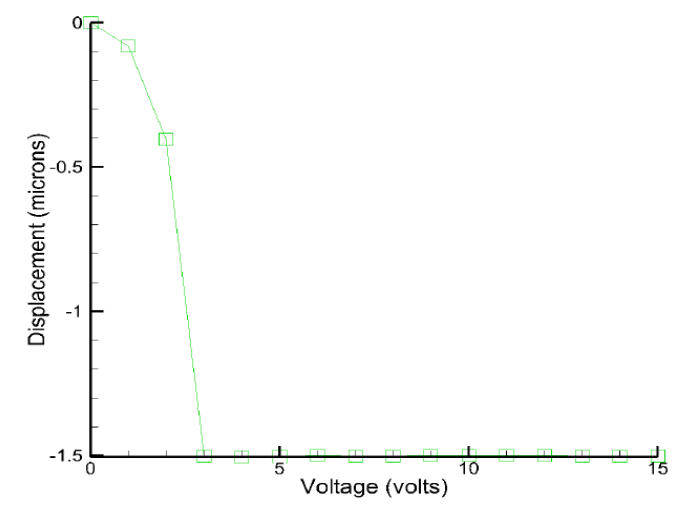

Figure 10. Pull in Voltage Result during the displacement designed using COVENTOR WARE software

\section{CONCLUSION}

A new model of shunt capacitive MEMS switch is designed and analysed. The proposed MEMS switch has better performances in both ON and OFF states. In UP (ON) state, the return loss and insertion loss are very good as per the requirement likewise in DOWN (OFF) state, the return loss and isolation 
parameters also show the very best result. Therefore this proposed switch offers low losses and high isolation value at high very range from 0 to $40 \mathrm{GHz}$. From this frequency range, proposed device is most suitable for radar and satellite communicatios. In other hand, the mass of designed switch is also decreased by the use of slots on the bridge surface and due to this the spring constat becomes lower and finally the pull in voltage $(\mathrm{Vp})$ is reduce to $3 \mathrm{~V}$. The compactness and stickiness of the switch during the contact with electrode can also be minimized by using the cylindrical holes on bridge contact surface.

\section{REFERENCES}

[1] T. R. Hsu, "MEMS \&Microsystems Design and Manufacture," McGraw Hill, 2002.

[2] G. M. Rebeiz, "RF MEMS Theory, Design, and Technology," A John Wiley \& Sons Publication, 2003.

[3] M. I. Younis, "Modelling and Simulation of microelectromechanical systems in Multi-Physics Fields," Ph.D Thesis, Virginia Polytechnic Institute and State University, Blacksburg, Virginia, Jun 2004.

[4] O. E. Maleky, et al., "Miniature design of T-Shaped frequency Reconfigurable antenna for S-Band Application using Switching Technique," International Journal of Electrical and Computer Engineering (IJECE), vol. 7, pp. 2426-2433, Oct 2017.

[5] R. P. Feynman, "There's Plenty ofRoom at the Bottom," Presented at the American Physical Society Meeting in Pasadena CA, Dec 1959.

[6] R. T. Howe, "Surface Micromachiningformicrosensors and microactuators," Journal of Vac. Sci. Technology, vol. 6, pp. 1809-1813, Dec 1988.

[7] Y. Mafinejad, et al., "Low Actuation Wideband RF MEMS shunt Capacitive Switch," 2012 International Workshop on Information and Electronics Engineering (IWIEE), SciVerse ScienceDirect, Elsevier, Procedia Engineering, vol. 29, pp. 1292-1297, 2012.

[8] R. Sharma and D. R. Shah, "Design and Analysis of MEMS Capacitive Shunt Type Switch for RF Application," in International Journal of Engineering Sciences \& Research Technology (IJESRT), vol. 5, pp. 179-184, Nov 2016.

[9] S. Balachandran, et al., "High power nanocrystalline diamond RF MEMS- A combined look at mechanical and microwave properties," in Microwaves, Communications, Antennas and Electronic Systems, 2008. COMCAS 2008. IEEE International. Conference on, 2008.

[10] L. S. Dae, et al., "A novel pull-up type RF MEMS switch with low actuation voltage," Microwave and Wireless Components Letters, IEEE, vol. 15, pp. 856-858, 2005.

[11] J. Naghar, et al., "Design Study of a Miniaturized Multi layered Antenna in -package for 2.4 GHZ Wireless Communication," International Journal of Electrical and Computer Engineering (IJECE), vol. 8, pp. 3627-3635, Oct 2018.

[12] R. Malmqvist, et al., "Design, packaging and reliability aspects of RF MEMS circuits fabricated using a GaAs MMIC foundry process technology," in Microwave Conf. (EuMC), 2010 European, 2010.

[13] J. Ruan, et al., "ESD stress in RF-MEMS capacitive switches: The influence of dielectric material deposition method," in Reliability Physics Symposium, 2009 IEEE International, 2009.

[14] A. K. Sahu and B. K. Sarkar, "A Novel Low Actuation Voltage RF MEMS Shunt Capacitive Switch,” IEEE, 2009.

[15] E. R. Kusumawati, et al., "Optically Switched Frequency for Reconfigurable Dipole Antenna Using Photodiode Switches," TELKOMNIKA Telecommunication Computing Electronics and Control, vol. 14, pp. 1351-1355, Dec 2016.

[16] S. P. Pacheco, et al., "Design of Low Actuation Voltage RF MEMS Switch," 2000 IEEE MTT-S Digest, pp. 165$168,2000$.

[17] C. L. Dai, et al., "Design and Fabrication of RF MEMS Switch. By 1; the CMOS Process," Tamkang Journal of Science and Engineering, vol. 8, pp. 197-202, 2005.

[18] C. Calaza, et al., "Electromechanical characterization of low actuation voltage RF MEMS capacitive switches based on DC," CV measurements. Microelectronic engineering, vol. 84, pp. 1358-1362, 2007.

[19] H. C. Lee, et al., "Piezoelectrically actuated RF MEMS DC contact switches with low voltage operation," Microwave and Wireless Components Letters, IEEE, vol. 15, pp. 202-204, 2005.

[20] P. Sagar and J. Bhalani, "Near Optimal Receive Antenna Selection Scheme for MIMO System under Spatially Correlated Channel," International Journal of Electrical and Computer Engineering (IJECE), vol. 8, pp. 37- 32, Oct 2018.

[21] C. Goldsmith, et al., "High-cycle life testing of RF MEMS switches," IEEE, 2007.

[22] J. H. Park, et al., "A fully wafer-level packaged RF MEMS switch with low actuation voltage using a piezoelectric actuator," Journal of Micromechanics and Microengineering, vol. 16, pp. 2281, 2006.

[23] J. Park, et al., "A non-contact-type RF MEMS switch for 24-GHz radar applications," Microelectromechanical Systems Journal of, vol. 18, pp. 163-173, 2009.

[24] S. Kang, et al., "See-saw type RF MEMS switch with narrow gap vertical comb," J. Semicond. Technol. Sci, vol. 7, pp. 177-82, 2007.

[25] B. Mansfield, "Fabrication of MEMS Devices," New Jersey Nanotechnology Consortium.

[26] A. R. Gupta, et al., "RF-MEMS Shunt Switch for Satellite Communication," SASTECH, vol. V, Apr 2005.

[27] C. Goldsmith, et al., "Characterizations of Micromachined Switches at Microwave Frequencies," IEEE MTT-S International, pp. 1141-1144, 1996.

[28] Ansoft Corporation, "HFSS." www.ansoft.com. 